\title{
Protective effect of berberine against tacrolimus-induced nephrotoxicity in LLC-PK1 cells
}

Hyuk-Jai Jang, Min-Jae Jung, Mi-Young Oh

Department of Surgery, Gangneung Asan Hospital, Gangneung, Korea

Background: Tacrolimus (FK506) is an immunosuppressant agent that is frequently used to prevent rejection of solid organs upon transplant. However, nephrotoxicity due to apoptosis and inflammatory response mediated by FK506 limit its usefulness. Berberine (BBR), a bioactive isoquinoline derivative alkaloid, found in many medicinal plants which is known to be an antioxidant and anti-inflammation compound. In the present study, the protective effect of berberine against FK506-induced damage in LLCPK1 pig kidney epithelial cells was investigated.

Methods: LLC-PK1 cells were exposed to FK506 with Berberine, and cell viability was measured. Western blotting and RT-PCR analyses evaluated protein or gene expression of MDA, HO-1, Bcl-2, Bax, tumor necrosis factor-a (TNF- $\alpha$ ), kidney injury molecule-1 (KIM-1), toll-like receptor-4 (TLR-4), and high mobility group box 1 protein (HMGB1) expression were assessed. The number of apoptotic cells was measured using an annexin V/PI staining with flow cytometry.

Results: Reduction in cell viability by 50 mM FK506 was ameliorated significantly by cotreatment with berberine. MDA, KIM-1, TNF- $\alpha$, Bax, TLR-4, and HMGB1, increased markedly in LLC-PK1 cells treated with FK506 and significantly decreased after cotreatment with berberine. HO-1 and Bcl-2 significantly increased in LLC-PK1 cells treated with FK506 after cotreatment with berberine. Moreover, flow cytometry assay showed that apoptotic cell death was increased by FK506 treatment, whereas it was significantly decreased after cotreatment with berberine.

Conclusions: These results collectively provide therapeutic evidence that berberine ameliorates the FK506-induced renal damage via antioxidant effect and inhibiting apoptosis and inflammation.

Corresponding author: Hyuk-Jai Jang

E-mail: jhj@gnah.co.kr

(c) The Korean Society for Transplantation

This is an Open Access article distributed under the terms of the Creative Commons Attribution Non-Commercial License (http://creativecommons.org/licenses/by-nc/4.0/) which permits unrestricted non-commercial use, distribution, and reproduction in any medium, provided the original work is properly cited. 